\title{
Antithrombotic Therapy in Peripheral Artery Disease
}

\section{Antithrombotic Therapy and Prevention of Thrombosis, 9th ed: American College of Chest Physicians Evidence-Based Clinical Practice Guidelines}

\author{
Pablo Alonso-Coello, MD, PhD; Sergi Bellmunt, MD; Catherine McGorrian, MBBCh, BAO; \\ Sonia S. Anand, MD, PhD; Randolph Guzman, MD, RVT; Michael H. Criqui, MD, MPH; \\ Elie A. Akl, MD, MPH, PhD; Per Olav Vandvik, MD, PhD; Maarten G. Lansberg, MD, PhD; \\ Gordon H. Guyatt, MD, FCCP; and Frederick A. Spencer, MD
}

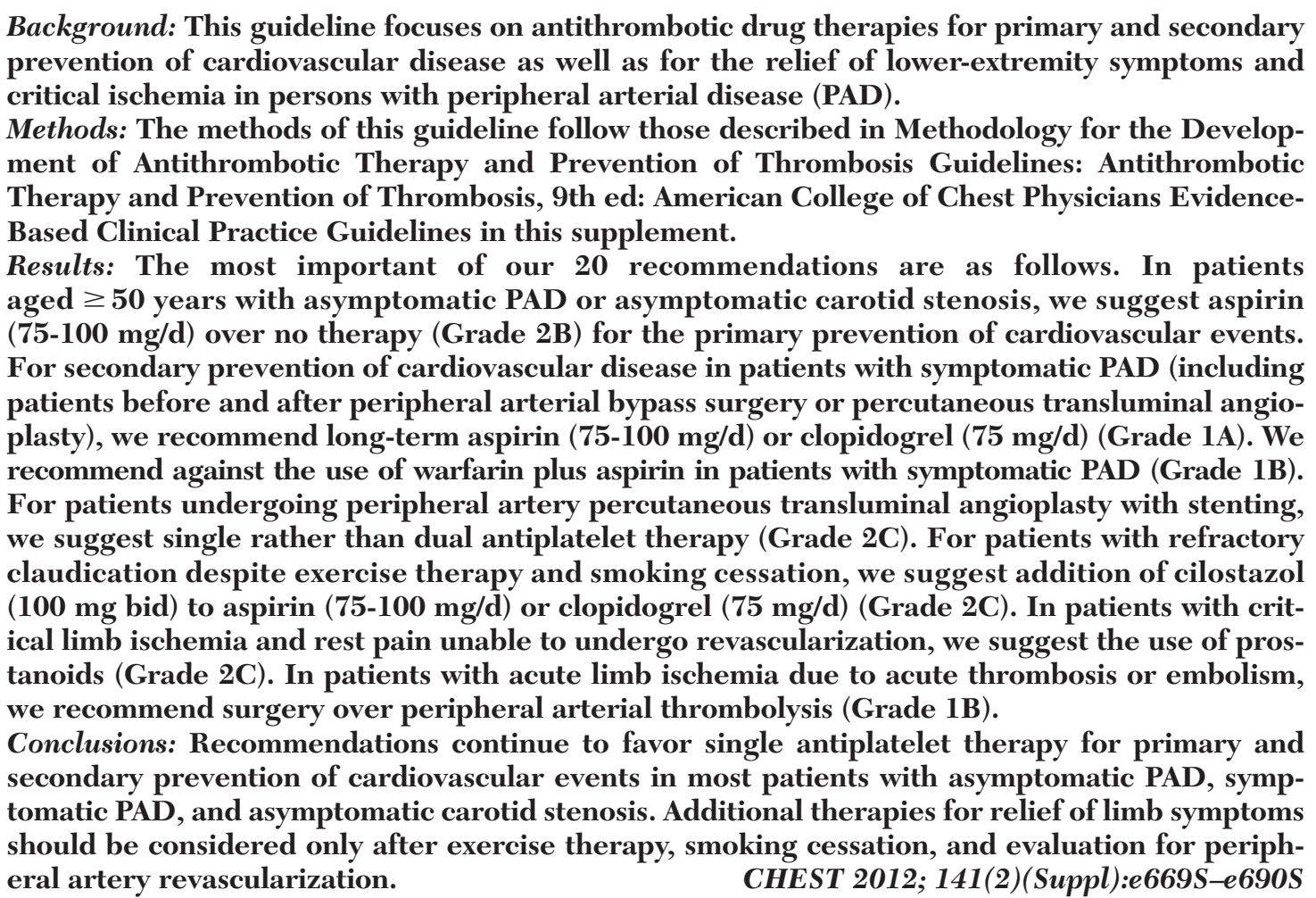

Abbreviations: $\mathrm{ABI}=$ ankle brachial index; $\mathrm{CAD}=$ coronary artery disease; $\mathrm{CAPRIE}=$ Clopidogrel vs Aspirin in Patients at risk for Ischemic Events; $\mathrm{MI}=$ myocardial infarction; $\mathrm{MWD}=$ maximum walking distance; PAD = peripheral arterial disease; $\mathrm{PTA}=$ percutaneous transluminal angioplasty; $\mathrm{RCT}=$ randomized controlled trial; $\mathrm{RR}=$ risk ratio; rt-PA $=$ recombinant tissue-type plasminogen activator 
SUMMARY OF RECOMMENDATIONS

Note on Shaded Text: Throughout this guideline, shading is used within the summary of recommendations sections to indicate recommendations that are newly added or have been changed since the publication of Antithrombotic and Thrombolytic Therapy: American College of Chest Physicians EvidenceBased Clinical Practice Guidelines (8th Edition). Recommendations that remain unchanged are not shaded.

2.1. For persons with asymptomatic peripheral arterial disease (PAD), we suggest aspirin 75 to $100 \mathrm{mg}$ daily over no aspirin therapy (Grade $2 \mathrm{~B}$ ).

Remarks: Aspirin slightly reduces total mortality regardless of cardiovascular risk profile if taken over 10 years. In people at moderate to high risk of cardiovascular events, the reduction in myocardial infarction (MI) is closely balanced with an increase in major bleeds. Whatever their risk status, people who are averse to taking medication over a prolonged time period for very small benefits will be disinclined to use aspirin for primary prophylaxis. Individuals who

Revision accepted August 31, 2011

Affiliations: From the Iberoamerican Cochrane Centre (Dr Alonso-Coello), CIBERESP-IIB Sant Pau, Barcelona, Spain; Angiology (Dr Bellmunt), Vascular and Endovascular Surgery Department, Hospital de la Santa Creu i Sant Pau, Barcelona, Spain; The Heart House (Dr McGorrian), Mater Misericordiae University Hospital, Dublin, Ireland; Departments of Medicine and Clinical Epidemiology and Biostatistics (Drs Anand and Guyatt), McMaster University, Hamilton, ON, Canada; Section Vascular Surgery (Dr Guzman), University of Manitoba, St Boniface Hospital, Winnipeg, MB, Canada; Department of Family and Preventive Medicine (Dr Criqui), University of California San Diego School of Medicine, La Jolla, CA; Department of Medicine (Dr Akl), State University of New York at Buffalo, Buffalo, NY; Norwegian Knowledge Centre for the Health Services and Department of Medicine Gjøvik (Dr Vandvik), Innlandet Hospital Trust, Gjøvik, Norway; Stanford Stroke Center (Dr Lansberg), Stanford University Medical Center, Palo Alto, CA; and Department of Medicine (Dr Spencer), McMaster University, Hamilton, ON, Canada. Funding/Support: The Antithrombotic Therapy and Prevention of Thrombosis, 9th ed: American College of Chest Physicians Evidence-Based Clinical Practice Guidelines received support from the National Heart, Lung, and Blood Institute [R13 HL104758] and Bayer Schering Pharma AG. Support in the form of educational grants were also provided by Bristol-Myers Squibb; Pfizer, Inc; Canyon Pharmaceuticals; and sanofi-aventis US.

Disclaimer: American College of Chest Physician guidelines are intended for general information only, are not medical advice, and do not replace professional medical care and physician advice, which always should be sought for any medical condition. The complete disclaimer for this guideline can be accessed at http:// chestjournal.chestpubs.org/content/141/2_suppl/1S.

Correspondence to: Frederick A. Spencer, MD, Department of Medicine, McMaster University, St Joseph's Health Care, 50 Charlton Ave E, Hamilton, ON, L8N 4A6, Canada; e-mail: fspence@mcmaster.ca

C) 2012 American College of Chest Physicians. Reproduction of this article is prohibited without written permission from the American College of Chest Physicians (http://www.chestpubs.org/ site/misc/reprints.xhtml).

DOI: $10.1378 /$ chest.11-2307 value preventing an MI substantially higher than avoiding a GI bleed, if they are in the moderate or high cardiovascular risk group, will be more likely to choose aspirin.

3.1-3.4. For secondary prevention patients with symptomatic PAD, we recommend one of the two following antithrombotic regimens to be continued long term over no antithrombotic treatment: aspirin 75 to $100 \mathrm{mg}$ daily or clopidogrel $75 \mathrm{mg}$ daily (all Grade $1 \mathrm{~A}$ ). We suggest not to use dual antiplatelet therapy with aspirin plus clopidogrel (Grade 2B). We recommend not to use an antiplatelet agent with moderate-intensity warfarin (Grade 1B).

4.1-4.4. For patients with intermittent claudication refractory to exercise therapy (and smoking cessation), we suggest the use of cilostazol in addition to previously recommended antithrombotic therapies (aspirin 75-100 mg daily or clopidogrel $75 \mathrm{mg}$ daily) (Grade $2 \mathrm{C}$ ); we suggest against the use of pentoxifylline, heparinoids, or prostanoids (Grade 2C).

5.1. For patients with symptomatic PAD and critical leg ischemia/rest pain who are not candidates for vascular intervention, we suggest the use of prostanoids in addition to previously recommended antithrombotic therapies (aspirin 75-100 $\mathrm{mg}$ daily or clopidogrel $75 \mathrm{mg}$ daily) (Grade 2C).

Values and preferences: Patients who do not value uncertain relief of rest pain and ulcer healing greater than avoidance of a high likelihood of drug-related side effects will be disinclined to take prostanoids.

6.1-6.3. In patients with acute limb ischemia due to arterial emboli or thrombosis, we suggest immediate systemic anticoagulation with unfractionated heparin over no anticoagulation (Grade 2C); we suggest reperfusion therapy (surgery or intraarterial thrombolysis) over no reperfusion therapy (Grade $2 \mathrm{C}$ ); we recommend surgery over intraarterial thrombolysis (Grade 1B). In patients undergoing intraarterial thrombolysis, we suggest recombinant tissuetype plasminogen activator (rt-PA) or urokinase over streptokinase (Grade 2C).

7.1. For patients undergoing peripheral artery percutaneous transluminal angioplasty (PTA) with or without stenting, we recommend longterm aspirin (75-100 mg/day) or clopidogrel (75 mg/day) (Grade 1A). For patients undergoing peripheral artery PTA with stenting, we suggest 
single rather than dual antiplatelet therapy (Grade 2C).

Values and preferences: Patients who place a high value on an uncertain reduction in the risk of limb loss and a relatively low value on avoiding a definite increased risk of bleeding are more likely to choose to use dual antiplatelet therapy.

8.1-8.4. We recommend one of the following antithrombotic regimens to be continued longterm following peripheral artery bypass graft surgery over no antithrombotic treatment: aspirin 75 to $100 \mathrm{mg}$ daily or clopidogrel $75 \mathrm{mg}$ daily (all Grade 1A). We recommend single antiplatelet therapy over antiplatelet therapy and warfarin (Grade 1B). In patients undergoing below-knee bypass graft surgery with prosthetic grafts, we suggest clopidogrel $75 \mathrm{mg} / \mathrm{d}$ plus aspirin $(75-100 \mathrm{mg} / \mathrm{d})$ over aspirin alone for 1 year (Grade 2C). For all other patients, we suggest single over dual antiplatelet therapy (Grade $2 \mathrm{~B}$ ).

9.1. For persons with asymptomatic carotid stenosis, we suggest aspirin 75 to $100 \mathrm{mg}$ daily over no aspirin therapy (Grade $2 \mathrm{~B}$ ).

Remarks: Aspirin slightly reduces total mortality regardless of cardiovascular risk profile if taken over 10 years. In people at moderate to high risk of cardiovascular events, the reduction in MI is closely balanced with an increase in major bleeds. Whatever their risk status, people who are averse to taking medication over a prolonged time period for very small benefits will be disinclined to use aspirin for primary prophylaxis.

9.2-9.3. In patients with symptomatic carotid stenosis (including recent carotid endarterectomy), we recommend long-term antiplatelet therapy with clopidogrel ( $75 \mathrm{mg}$ once daily) or aspirinextended-release dipyridamole $(25 \mathrm{mg} / 200 \mathrm{mg}$ bid) or aspirin (75-100 mg once daily) over no antiplatelet therapy (Grade 1A). We suggest either clopidogrel (75 mg once daily) or aspirin-extendedrelease dipyridamole $(25 \mathrm{mg} / 200 \mathrm{mg}$ bid) over aspirin (75-100 mg) (Grade 2B).

$\mathbf{T}$ his article focuses on the use of antithrombotic drugs in patients with peripheral arterial disease (PAD). PAD is associated with a high prevalence of atherosclerosis in other vascular beds. The leading causes of morbidity and mortality in patients with PAD are myocardial infarction (MI) and stroke; therefore, as in patients with coronary artery disease (CAD), the primary benefit of antithrombotic therapy in this patient population is prevention of vascular events and mortality. The patient-important outcomes (ie, total mortality, nonfatal MI, nonfatal stroke, major nonfatal extracranial bleed) are the same outcomes considered for recommendations for CAD and stroke. However, we review the effects of antithrombotic therapy on outcomes specific to PAD (eg, rest pain of the limbs, quality of life, or amputation).

Studies evaluating antithrombotic therapy immediately following peripheral bypass graft surgery or percutaneous endovascular procedures generally have used graft patency or reocclusion as the primary end point. These outcomes are surrogates for patientimportant outcomes of quality of life and limb amputation, which are seldom reported.

We consider the desirable and undesirable consequences of antithrombotic therapy in the following populations or patient groups: (1) persons with asymptomatic PAD, (2) patients with symptomatic PAD (including those with claudication or critical [chronic] limb ischemia and rest pain or prior peripheral arterial revascularization), (3) patients with acute limb ischemia and threatened limb loss, (4) patients following peripheral arterial revascularization, and (5) persons with asymptomatic and symptomatic carotid stenosis. Table 1 and Table S1 describe both the question definition (ie, population, intervention, comparator, and outcome) and the study types considered for each question. (Tables that contain an "S" before the number denote supplementary tables not contained in the body of the article and available instead in an online data supplement. See the "Acknowledgments" for more information.)

High-quality evidence supports an effect of aspirin on vascular mortality. In addition, a recent metaanalysis provided moderate-quality evidence that long-term use of aspirin reduces mortality from specific cancer types. ${ }^{1}$ In a population of patients with symptomatic vascular disease, vascular disease and cancer are the leading causes of death. Therefore, we have chosen total mortality over a 10 -year period as the main outcome of interest. When data are available, we included fatal intracranial or extracranial bleeding with vascular death or total mortality under the general category of antithrombotic therapy-related deaths. Nonfatal hemorrhagic strokes and ischemic strokes are included together as nonfatal strokes. Although the former is a complication and decrease in the latter is a beneficial effect of antithrombotic therapy, their impact on patient morbidity is similar.

\subsection{Methods}

\section{Estimation of Baseline Risks and Absolute Effects of Treatment}

In order to estimate absolute benefits and harms associated with a given therapy, we performed the following steps. First, 


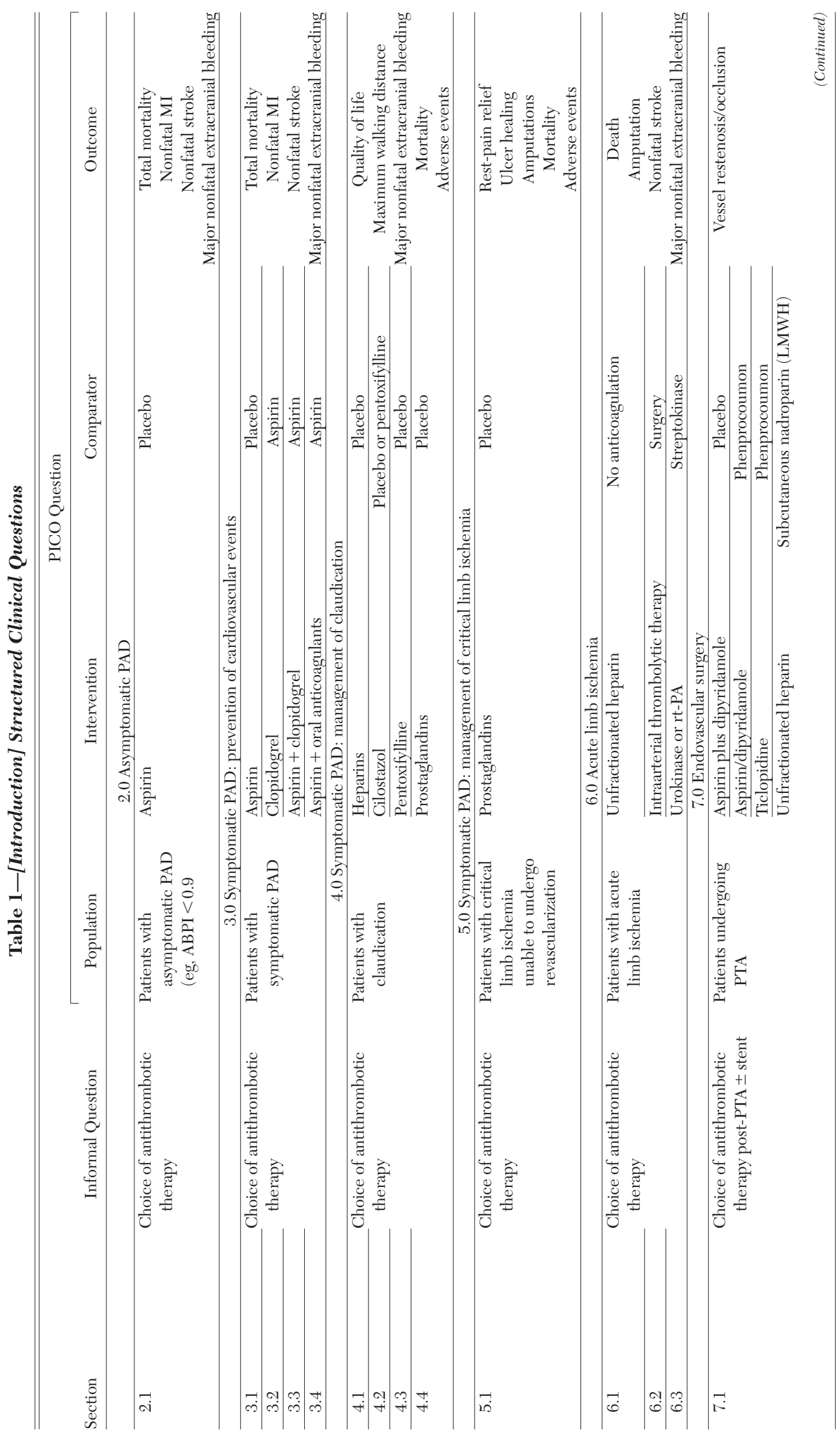




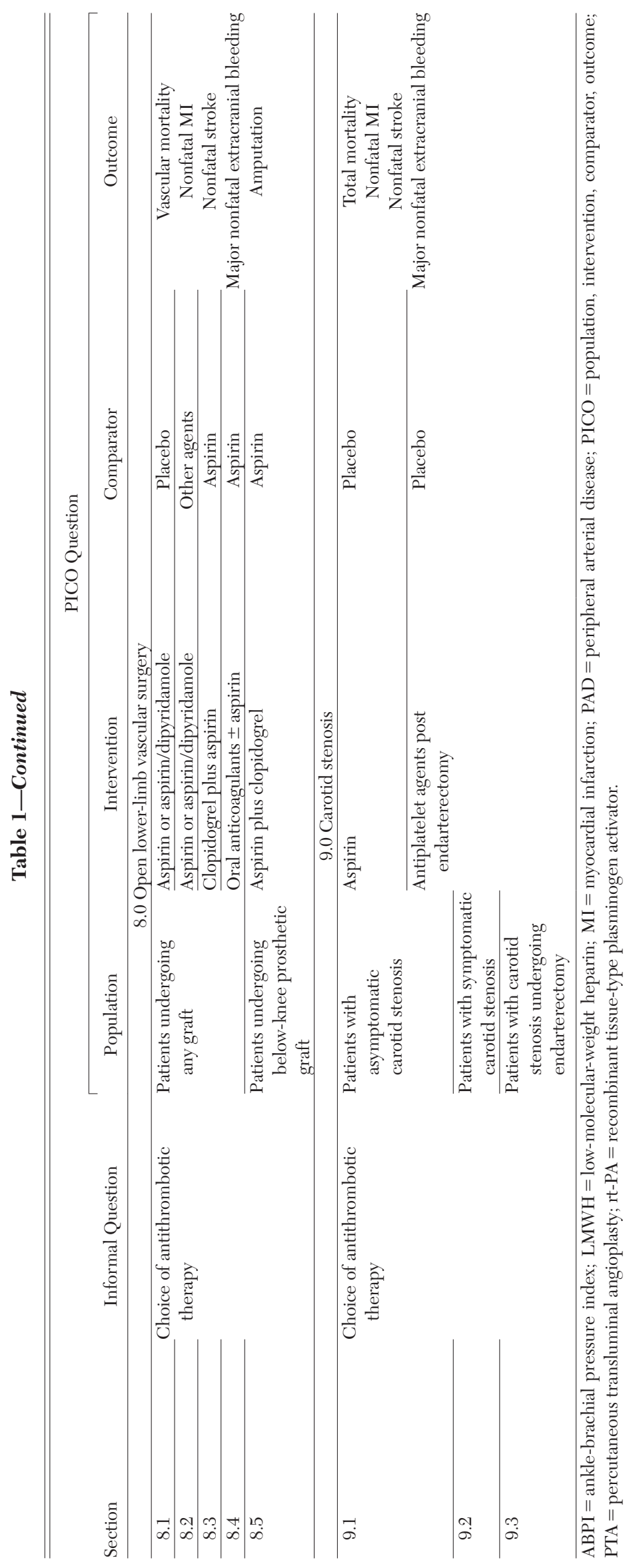


we generated relative effect estimates (relative risks) from the highest-quality published meta-analysis of randomized controlled trials (RCTs). If no such meta-analyses were available or were out of date, we conducted our own meta-analyses of relevant RCTs or used relative risk estimates from single RCTs in the absence of other relevant RCTs.

Ideally, in order to approximate the benefit of a given therapy in the real world, estimates of baseline risk (control group risks) would be derived from population-based observational studies. Unfortunately, for most of our clinical questions, we were unable to identify observational studies of sufficient quality that reported all relevant outcomes. In such cases, we derived control group risk estimates from a representative control arm of a relevant metaanalysis or RCT and adjusted them to our specified time frame. Detailed explanations of our choices are presented in each section.

Values and Preferences

The relative weight given to outcomes (eg, an extracranial bleed compared with an MI or a stroke) greatly affects the trade-offs between desirable and undesirable consequences of antithrombotic therapy. Unfortunately, limited data guide us with respect to the relative impact of these events on a patient's quality of life. ${ }^{2}$ As described in Guyatt et $a l,{ }^{3}$ in this supplement we have used ratings from participating guideline panelists' estimates of patient valuation of the outcomes of interest. The ratings suggest that nonfatal major extracranial bleeding (which is usually readily treated and with few long-lasting consequences) carries only slightly less weight than a nonfatal MI (which also often has limited long-term consequences) but substantially less weight than a stroke (which often is associated with long-term disability). Our decisions are based on a disutility or negative weight of stroke of three times the disutility of a major extracranial bleed.

Trade-offs between desirable and undesirable consequences of alternative management strategies sometimes represent closecall situations. In making recommendations in such situations, we have taken a primum non nocere (first do no harm) approach, placing the burden of proof with those who would claim a benefit of treatment. In other words, when a treatment is associated with uncertain benefit and an appreciable probability of important harm, we recommend against such treatment.

We identified the relevant evidence for our clinical questions with the assistance of a team of methodologists and medical librarians as outlined in Guyatt et al. ${ }^{3}$ Systematic literature searches for systematic reviews and original studies were performed until the date of January 15, 2010. After that date, we scanned the literature regularly, although this was not performed as systematic literature searches.

\subsection{Primary Prevention of Cardiovascular Events in Patients With Asymptomatic PAD}

As in the article by Vandvik et al ${ }^{4}$ of this supplement, primary prevention refers to the use of an intervention to prevent events prior to any clinically manifested disease. Hence, even though nearly every 70 -year-old man or woman has significant vascular changes, they are candidates for primary (as opposed to secondary) prevention unless they have clinically manifested vascular disease (ie, claudication; history of peripheral vascular procedures; known history of CAD, MI, or stroke).

Most asymptomatic patients with PAD will be identified through ankle-brachial index (ABI) screening. The ABI is the ratio of the highest systolic BP in the lower limb to that of the arm. This relatively simple clinical test was originally used to confirm the diagnosis of PAD and assess its severity. Low ABI $(<0.90)$ has been shown to be an independent predictor of MI, stroke, and vascular mortality independent of other cardiovascular risk factors. ${ }^{5-9}$ The ABI, therefore, has been promoted as a simple, inexpensive, noninvasive screening tool for the assessment of future cardiovascular risk. In a meta-analysis of $\sim 48,000$ healthy men and women, $\mathrm{ABI}<0.90$ at baseline was associated with an approximate doubling of the 10-year mortality, cardiovascular mortality, and major coronary event rate after adjusting for the Framingham risk score. ${ }^{10}$

Therefore, when evaluating a patient for primary prevention with aspirin, we suggest using a risk stratification tool such as the Framingham risk score, which provides estimates of low $(<10 \%)$, moderate (10\%-20\%), and high risk (>20\%) of cardiovascular events over 10 years. If, in addition, the patient has an $\mathrm{ABI}<0.90$, we suggest doubling this score, thus possibly increasing the patient's risk from a low to moderate or a moderate to high category. ${ }^{10}$

\subsection{Aspirin}

We consider the evidence for aspirin therapy for the primary prevention of CAD (see section 1.1 in Vandvik et $\mathrm{al}^{4}$ in this supplement) applicable to patients with asymptomatic PAD. On the basis of an individual participant data meta-analysis, ${ }^{11}$ aspirin would be expected to prevent 19 and 31 nonfatal MIs and lead to 16 and 22 major extracranial bleeding events per 1,000 moderate- and high-risk patients treated, respectively (Table S2). In addition, long-term aspirin use has been associated with a significant decrease in cancer mortality, ${ }^{12}$ likely contributing to the decrease in total mortality associated with longterm aspirin therapy observed in another metaanalysis. ${ }^{13}$ On the basis of these data and regardless of vascular risk, aspirin use in 60-year-old men would also result in six fewer deaths (12 fewer to 0 fewer) per 1,000 patients treated for 10 years. The overall quality of evidence is moderate given the imprecision in the estimates for total mortality.

The relative effect of aspirin on prevention of vascular events, bleeding, and total mortality are likely similar in patients with cardiovascular risk factors, asymptomatic PAD, and asymptomatic carotid stenosis. Our recommendations for primary prevention in asymptomatic patients with PAD are therefore identical to those described in Vandvik et al. ${ }^{4}$

\section{Recommendation}

2.1. For persons with asymptomatic PAD, we suggest aspirin 75 to $100 \mathrm{mg}$ daily over no aspirin therapy (Grade $2 \mathrm{~B}$ ). 
Remarks: Aspirin slightly reduces total mortality regardless of cardiovascular risk profile if taken over 10 years. In people at moderate to high risk of cardiovascular events, the reduction in MI is closely balanced with an increase in major bleeding events. Whatever the risk status, people averse to taking medication over a prolonged time period for very small benefits will be disinclined to use aspirin for primary prophylaxis. Individuals who value preventing an MI substantially higher than avoiding a GI bleed, if they are in the moderate or high cardiovascular risk strata, will be more likely to choose aspirin.

\subsection{Secondary Prevention of Cardiovascular Events in Patients With Symptomatic PAD}

\section{1-3.3 Antiplatelet Therapies for Secondary Prevention of Cardiovascular Events in}

Patients With Symptomatic PAD

Because antiplatelet therapy would be expected to result in similar relative reductions in vascular events such as MI or stroke in patients with PAD or CAD, we considered RCTs enrolling patients with PAD, CAD, or both to support our recommendations for both conditions. Although many of the included studies conducted post hoc analyses limited to patients enrolled for symptomatic PAD, we did not find these subgroup analyses credible based on criteria proposed by Sun et al. ${ }^{14}$ Therefore, our recommendations for antiplatelet therapy as secondary prevention of cardiovascular events in symptomatic patients with PAD are identical to those described in sections 2.1.1, 2.1.2, 2.1.3, and 2.1.5 of Vandvik et al. ${ }^{4}$ For the reader's interest, we briefly review the pertinent evidence in the following sections.

\subsection{Aspirin}

Table S3 summarizes the quality of evidence and main findings from a meta-analysis of individual participant data from 16 randomized trials with 17,000 patients with established vascular disease (six trials of patients with previous MI and 10 of patients with previous transient ischemic attack or stroke). ${ }^{11}$ In this population at high risk for a serious vascular event ( $8.2 \%$ yearly risk), aspirin significantly reduced total mortality, nonfatal MI, and nonfatal stroke but increased nonfatal extracranial bleeding events. The number of vascular events and total deaths prevented was far greater than the number of bleeding events that resulted from aspirin.

\subsection{Clopidogrel vs Aspirin}

The Clopidogrel vs Aspirin in Patients at Risk for Ischemic Events (CAPRIE) trial is the only ran- domized trial that directly compared clopidogrel and aspirin in secondary prevention of cardiovascular events, and we consider this trial to be the most credible source of evidence. ${ }^{15}$ More than 19,000 patients with atherosclerotic vascular disease manifested as a recent stroke, recent MI, or symptomatic PAD received clopidogrel or aspirin. After a mean follow-up of 1.9 years, clopidogrel was associated with a possible reduction in nonfatal MI and nonfatal extracranial bleeding and little or no effect on total mortality. Table S4 summarizes the quality of evidence and main findings of the CAPRIE trial. The results indicate no effect of clopidogrel on total mortality compared with aspirin. These results are consistent with a meta-analysis of 10 studies examining the effects of thienopyridine derivatives (eg, clopidogrel, ticlopidine) vs aspirin in patients at high vascular risk. ${ }^{16}$

\subsection{Dual Antiplatelet Therapy With Clopidogrel and Aspirin vs Single Antiplatelet Therapy}

A Cochrane systematic review evaluated shortand long-term dual antiplatelet therapy in patients with established CAD. ${ }^{17}$ Only one large-scale RCT, the Clopidogrel for High Atherothrombotic Risk and Ischemic Stabilization, Management, and Avoidance (CHARISMA) trial, has evaluated the long-term efficacy of clopidogrel and aspirin vs aspirin alone. ${ }^{18}$ This trial followed 15,603 patients with established vascular disease or multiple risk factors for a mean period of 28 months. Table S5 summarizes the quality of evidence and findings from this trial. Results of the study failed to demonstrate or exclude an effect of dual antiplatelet therapy relative to aspirin on total mortality or nonfatal MI. Dual antiplatelet therapy was associated with a possible reduction in nonfatal stroke and a possible increase in nonfatal extracranial bleeding. We considered the quality of evidence to be moderate because of imprecise effect estimates for all outcomes. Although this study included patients with other vascular diseases, we considered its findings directly applicable to patients with symptomatic PAD. We did not deem subgroup analyses suggesting different effects of dual antiplatelet therapy in symptomatic vs asymptomatic patients to be credible. ${ }^{14}$

\subsection{Warfarin Plus Aspirin vs Aspirin Alone}

Although studies comparing warfarin to placebo or aspirin have been conducted in patients with PAD, these have been small in size and focused on PADspecific outcomes (eg, lower-extremity pain, bypass graft patency) rather than on rates of subsequent stroke, MI, or vascular death. Subsequent sections summarize these studies.

Of the available trials of patients with asymptomatic CAD comparing warfarin plus aspirin to aspirin 
alone, all were in the setting of a recent acute coronary syndrome, and a number had only short-term follow-up. It is unknown whether the response to warfarin therapy, particularly with respect to bleeding, might differ in patients with symptomatic CAD vs symptomatic PAD. Therefore, we used only RCTs specifically enrolling patients with symptomatic PAD for our evaluation of warfarin therapy.

For the comparison of warfarin plus aspirin vs aspirin alone for nonfatal vascular outcomes, we used the event rates from participants taking aspirin in a metaanalysis of 16 RCTs evaluating aspirin use vs no aspirin use in patients with vascular disease adjusted to a 5 -year time interval as our baseline risk estimate. ${ }^{10}$ Because this meta-analysis does not provide data on total mortality or nonfatal major extracranial bleeds, we derived baseline risk estimates from the aspirin arm in the CHARISMA trial (total mortality) and CAPRIE trial (major nonfatal extracranial bleeding events).15,18

We identified three RCTs evaluating warfarin (international normalized ratio, 2.0-3.0) plus aspirin vs aspirin alone in 3,048 patients with established PAD. ${ }^{19-21}$ Table 2 and Table S6 provide details about the quality of evidence and findings from our metaanalysis of the three included studies. Results failed to demonstrate or exclude an effect of warfarin plus aspirin vs aspirin alone on mortality, nonfatal MI, or nonfatal stroke. However, there was a significant increase in major bleeding events with warfarin plus aspirin compared with aspirin alone. The overall quality of evidence is low.

\section{Recommendation}

3.1-3.4. For secondary prevention in patients with symptomatic PAD, we recommend one of the two following antithrombotic regimens to be continued long term over no antithrombotic treatment: aspirin $\mathbf{7 5}$ to $100 \mathrm{mg}$ daily or clopidogrel $75 \mathrm{mg}$ daily (all Grade $1 \mathrm{~A}$ ). We suggest not to use dual antiplatelet therapy with aspirin plus clopidogrel (Grade $2 \mathrm{~B}$ ). We recommend not to use an antiplatelet agent with moderateintensity warfarin (Grade 1B).

\subsection{ANTITHROMBOTIC THERAPY FOR THE Management of Patients With Claudication}

In the previous section, we recommended aspirin or clopidogrel for the prevention of nonfatal MI, nonfatal stroke, or vascular death for all patients with symptomatic PAD. In this section, we evaluate other therapies with antiplatelet and antithrombotic properties (eg, cilostazol, pentoxifylline, prostanoids) for their effect on quality of life. Unfortunately, most studies have not evaluated quality of life as an outcome directly and often used walking distance as a surrogate. We make inferences regarding quality of life based on these data, inferences that are less certain because of indirectness. Because these therapies have not been shown to have an impact on cardiovascular events, they are considered only as possible additions to previously recommended antiplatelet treatments.

Patients with intermittent claudication have lowerextremity discomfort with walking, thereby limiting activity. In general, claudication itself is not associated with limb loss and is responsive to smoking cessation and exercise therapy. Cessation of tobacco use can significantly reduce lower-extremity symptoms and progression of PAD. ${ }^{22,23}$ One systematic review suggested that structured exercise programs can improve maximal walking distance (MWD). ${ }^{24}$ Therefore, additional drug therapy should be considered only in patients who have troubling limitations even after smoking cessation and exercise therapy.

\section{Selection of Baseline Risk}

For the three comparisons of cilostazol, pentoxifylline, and prostanoids vs placebo, because controlled trials showed large improvements in walking test distance in patients in placebo groups, for the surrogate outcome of MWD, we used a control response rate of $80 \%$; that is, we assumed that $80 \%$ of untreated patients would show improvements in quality of life. We calculated the standardized mean differences, and when needed, we imputed SDs from other trials. We then converted standardized mean differences into risk differences ${ }^{25,26}$ and present the results as the proportion of patients who experience an important benefit in quality of life (inferred from MWD). For evaluation of bleeding risk associated with cilostazol compared with no cilostazol or placebo, we used the control group risk estimate from a systematic review of 10 RCTs evaluating cilostazol in addition to dual antiplatelet therapy in coronary percutaneous transluminal angioplasty (PTA) and stenting. ${ }^{27}$

\subsection{Cilostazol}

Cilostazol is a phosphodiesterase III inhibitor of platelet activation and relaxes vascular smooth muscle. Ten RCTs that compared cilostazol $100 \mathrm{mg}$ bid to placebo have been located in two systematic reviews. ${ }^{28,29}$ Pooling data from seven studies comparing cilostazol vs placebo suggested that regarding health-related quality of life (as inferred from MWD), patients receiving cilostazol are more likely to experience an important benefit than those receiving placebo (79 more per 1,000 [55 more to 100 more]) (Table 3, Table S7). Changes in quality of life were evaluated directly in four of the studies 


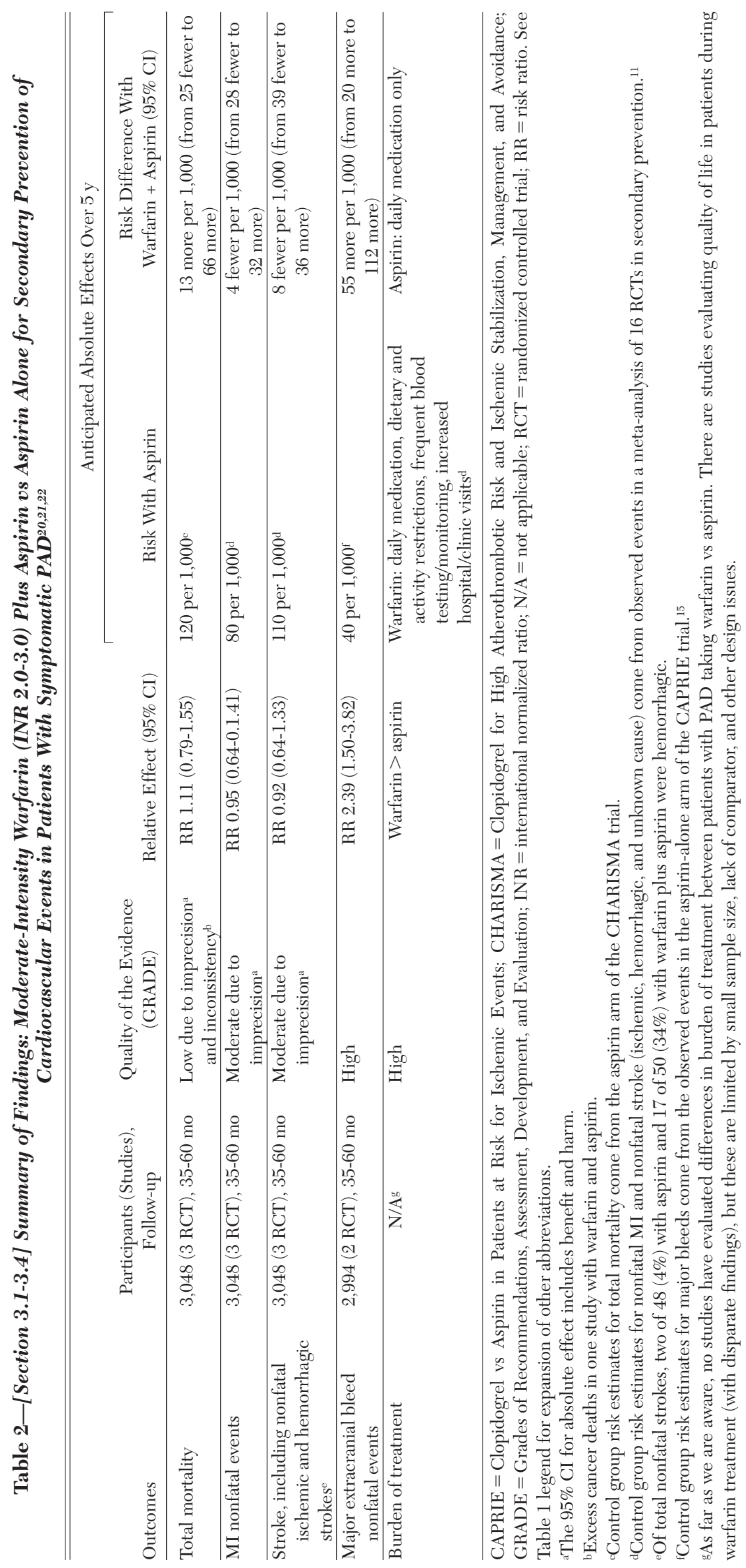




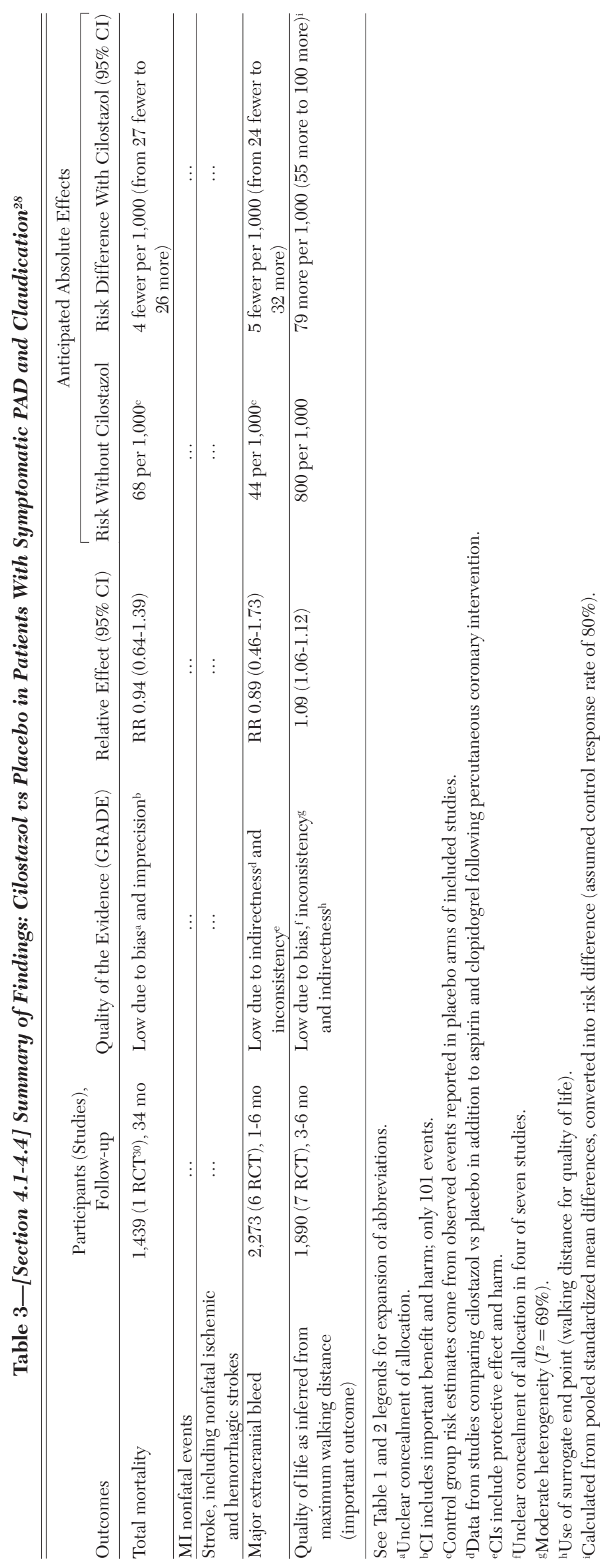


comparing cilostazol $100 \mathrm{mg}$ bid to placebo. ${ }^{31-34}$ All four trials reported results consistent with our inferences from MWD: a significant improvement in the physical health subscale of the SF-36 (Short Form Health Survey), suggesting an improvement in overall physical function. However, the overall healthrelated quality of life was not improved, with no changes in the mental health components (eg, social functioning, role-emotional subscale). In the largest of the trials, the results failed to demonstrate or exclude an effect of cilostazol on total mortality. ${ }^{30}$

Regarding quality of life (as inferred from MWD), patients receiving cilostazol $100 \mathrm{mg}$ bid were more likely to experience an important benefit than those receiving pentoxifylline..$^{35}$ There were no significant differences in total mortality or adverse events (any adverse event or serious adverse events).

A separate review of a pharmaceutical safety database included eight RCTs of patients with symptomatic PAD. ${ }^{36}$ The authors did not list the individual trials included in this database. There were 1,374 participants randomized to cilostazol (475 patient-years exposure) and 973 randomized to placebo (357 patient-years exposure). Although a formal meta-analysis does not appear to have been undertaken, the review reported no difference in rates of MI ( $1.0 \%$ vs $0.8 \%)$, stroke $(0.5 \%$ vs $0.5 \%)$, or death $(0.6 \%$ vs $0.5 \%)$ between patients with symptomatic PAD taking cilostazol or those taking placebo. ${ }^{36}$ Major or minor bleeding rates were not reported.

As we considered whether to add cilostazol to existing antithrombotic therapy, we relied on bleeding data from studies comparing cilostazol to no cilostazol in patients undergoing coronary stenting (and already taking aspirin and clopidogrel) to estimate bleeding risk associated with this therapy. A systematic review of cilostazol in patients undergoing percutaneous coronary intervention included 10 RCTs (2,809 patients) comparing triple therapy with aspirin, clopidogrel, and cilostazol to aspirin plus clopidogrel. ${ }^{27}$ Results failed to demonstrate or exclude an effect of cilostazol on major bleeding (risk ratio [RR], 0.89; 95\% CI, 0.46-1.73).

\subsection{Pentoxifylline}

Pentoxifylline was compared with placebo in six small RCTs in patients with intermittent claudication. A pooled analysis of these trials failed to demonstrate a difference between pentoxifylline and placebo in quality of life as inferred from MWD (31 more per 1,000 [47 less to 94 more]). ${ }^{29}$ Pentoxifylline was associated with more adverse events (96 more per 1,000 [21 more to 181 more]). The studies included had limitations in design and execution and showed marked variability, and there was an important risk of publication bias; thus, the overall quality of the evidence was deemed to be low.

\subsection{Heparins (Including Low-Molecular Weight Heparins)}

A Cochrane systematic review of the use of heparin products in patients with intermittent claudica$\operatorname{tion}^{37}$ identified five eligible studies (Table S8). ${ }^{38-42}$ In the pooled data, there were no deaths, no bleeding events, and nine cardiovascular events with no significant differences between heparins and placebo. Effects of heparin on walking distance were only evaluable from one RCT in which heparin 12,500 units subcutaneously daily or placebo were administered for two 3-month periods followed by 6 months of observation in a crossover design. Aspirin was administered throughout the 18-month period. ${ }^{38}$ Results failed to establish or exclude benefit or harm from heparin (112 more with improvement in quality of life per 1,000 [58 fewer to 149 more]) (Table S8).

\section{4 Prostanoids}

Prostaglandins (prostaglandin E1, prostaglandin I2, and their derivatives) are potent inhibitors of platelet activation, adhesion, and aggregation and have vasodilatory and antithrombotic effects. A metaanalysis of five studies (1,636 patients) suggested that with regard to quality of life as inferred from MWD, patients receiving prostaglandins are more likely to experience an important benefit than those receiving placebo (79 more per 1,000 [58 more to 98 more]) but have a higher risk of adverse events (RR, 2.61; 95\% CI, 1.40-4.85). ${ }^{43}$ There was substantial heterogeneity between study results $\left(I^{2}=64 \%\right)$. Results failed to demonstrate or exclude an effect of prostaglandins vs placebo on nonfatal stroke, nonfatal MI, revascularization, or death. The overall quality of the evidence is low due to risk of bias and imprecision and for quality of life, indirectness (Table S9).

Recommendation

\begin{abstract}
4.1-4.4. For patients with intermittent claudication refractory to exercise therapy and smoking cessation, we suggest the use of cilostazol in addition to previously recommended antithrombotic therapies (aspirin 75-100 $\mathrm{mg}$ daily or clopidogrel $75 \mathrm{mg}$ daily) (Grade $2 \mathrm{C}$ ); we suggest against the use of pentoxifylline, heparinoids, or prostanoids (Grade 2C).
\end{abstract}

\subsection{CRITICAL LIMB ISCHEMIA}

Patients with critical limb ischemia have inadequate resting blood flow to the lower limbs, resulting 
in rest pain, ulceration, and eventually gangrene and limb loss. Such patients are candidates for prompt revascularization. Pertinent outcomes include relief of pain, quality of life, and limb salvage.

\subsection{Prostanoids}

Investigators have also administered prostaglandins to patients with critical limb ischemia in hopes of relieving rest pain and healing ischemic ulcers. A Cochrane systematic review identified 13 studies comparing prostanoids to placebo in patients with critical limb ischemia without chance of rescue or reconstructive intervention. ${ }^{4}$ These studies measured outcomes in different ways. The authors of the review dealt with this variability by dichotomizing the continuous results. Pain relief was defined as any improvement on a validated pain scale. Ulcer healing was defined as any decrease in lesion surface area and presence of granulation tissue. The overall quality of the evidence is low because of limitations in design, imprecision, and inconsistency.

Prostanoids improved rest pain and ulcer healing (77 and 136 patients per 1,000 treated, respectively) but did not significantly prevent amputations or decrease mortality (Table 4, Table S10). Prostanoids were poorly tolerated, with $\sim 75 \%$ of subjects experiencing at least one adverse event compared with $31 \%$ of controls (the most commonly reported adverse effects were headache, nausea, vomiting, diarrhea, and facial flushing). A sensitivity analysis restricted to the eight highest-quality studies found similar results with respect to the five outcome variables.

Recommendation

\subsection{For patients with symptomatic PAD and critical leg ischemia/rest pain who are not can- didates for vascular intervention, we suggest the use of prostanoids in addition to previously recommended antithrombotic therapies (aspi- rin 75-100 $\mathrm{mg}$ daily or clopidogrel $75 \mathrm{mg}$ daily)} (Grade 2C).

Values and preferences: Patients who do not value uncertain relief of rest pain and ulcer healing greater than avoidance of a high likelihood of drug-related side effects will be disinclined to undergo prostanoid therapy.

\subsection{ACUTe Limb Ischemia}

Acute limb ischemia results from a sudden interruption of blood flow to an extremity. ${ }^{45}$ The most common causes of nontraumatic acute arterial occlusion are embolism and thrombosis. ${ }^{45-47}$ Approximately
$80 \%$ of peripheral emboli originate in the heart (eg, left atrial appendage, left ventricular apex, native and prosthetic cardiac valves). In the remaining cases, emboli originate from the aorta or peripheral vessels themselves or are of venous origin (paradoxical with migration through patent foramen ovale and atrial septal defect). Thrombotic occlusion is most commonly associated with advanced atherosclerosis, with slow progression of disease. ${ }^{47}$ The limb typically has developed a collateral blood supply, and the final occlusion of the stenotic vessel often is not immediately limb threatening. ${ }^{45,47}$

\subsection{Anticoagulation for Acute Limb Ischemia}

Regardless of the cause and level of acute limb ischemia, patients usually receive short-term anticoagulation treatment with therapeutic doses of heparin to reduce the extent of ischemic injury by preventing clot propagation and further embolism. Although the logic of this approach is widely accepted, there are no formal studies demonstrating improved outcomes with anticoagulation. The expected adverse effect of preoperative anticoagulant therapy is an increased risk of bleeding, including wound hematomas. To our knowledge, there are no randomized trials directly comparing unfractionated heparin with other anticoagulants in this setting.

\subsection{Thrombolysis vs Surgery for Acute Limb Ischemia}

Treatment of acute limb ischemia is directed at restoration of flow to the occluded artery, which is now commonly accomplished by either surgery or catheter-directed intraarterial thrombolysis. Although no formal data support either reperfusion therapy over anticoagulation alone or supportive care, the high risk of limb loss (and subsequent associated morbidity and mortality) without blood flow restoration has led to widespread use of both modalities.

Table 5 and Table S11 summarize the results from a meta-analysis that provides the best evidence regarding the comparative benefits and harms of intraarterial thrombolysis vs surgery. ${ }^{48}$ This metaanalysis presented data from five randomized trials of 1,180 patients. ${ }^{49-53}$ We provide absolute effect estimates based on control (surgical arm) event rates from these trials. In summary, thrombolysis compared with surgery appeared to have little or no effect on limb salvage but was associated with an increase risk in stroke ( 10 per 1,000 treated) and major bleeding (16 per 1,000 treated) at 30 days. Results failed to demonstrate or exclude an effect of thrombolysis vs surgery on amputation or death. We consider the overall quality of evidence to be moderate because of inconsistency and imprecision. 


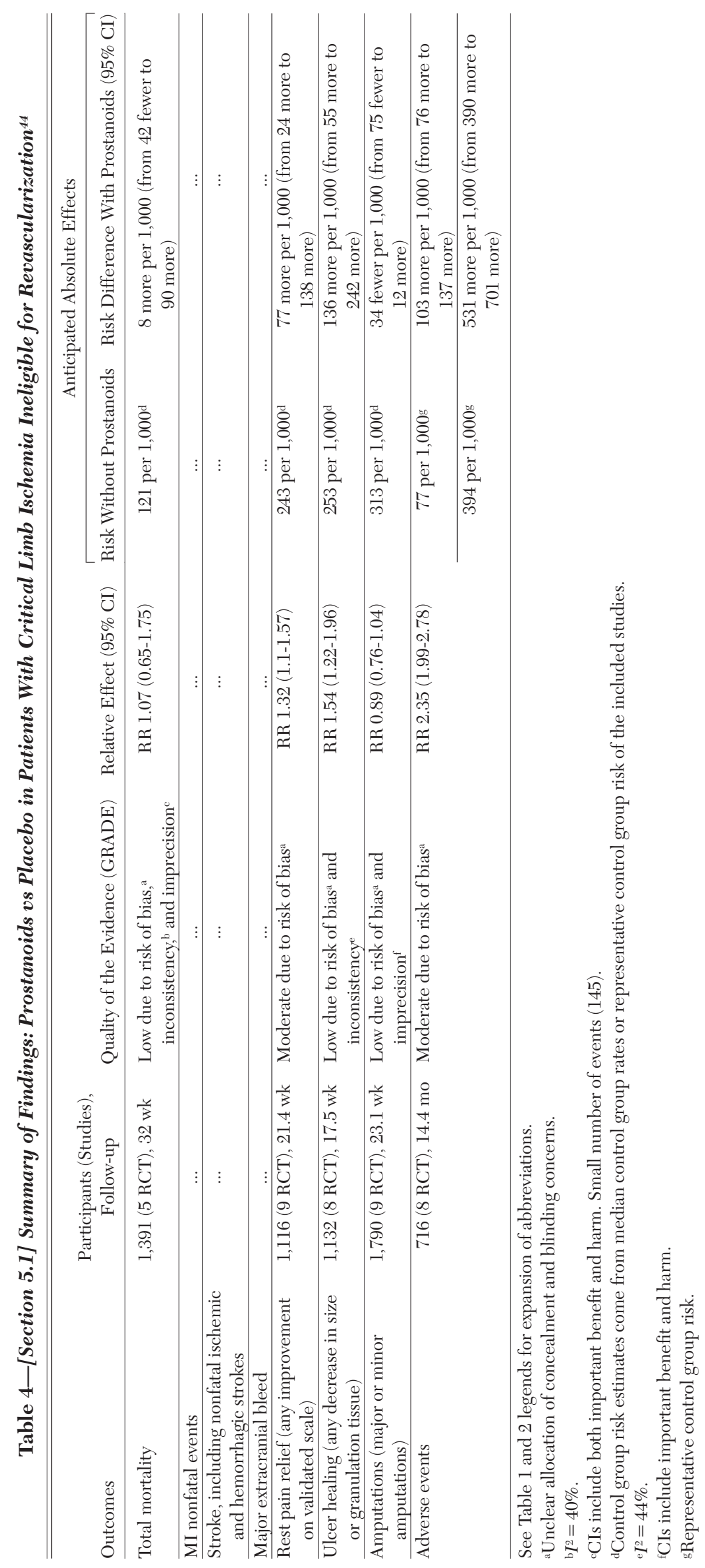




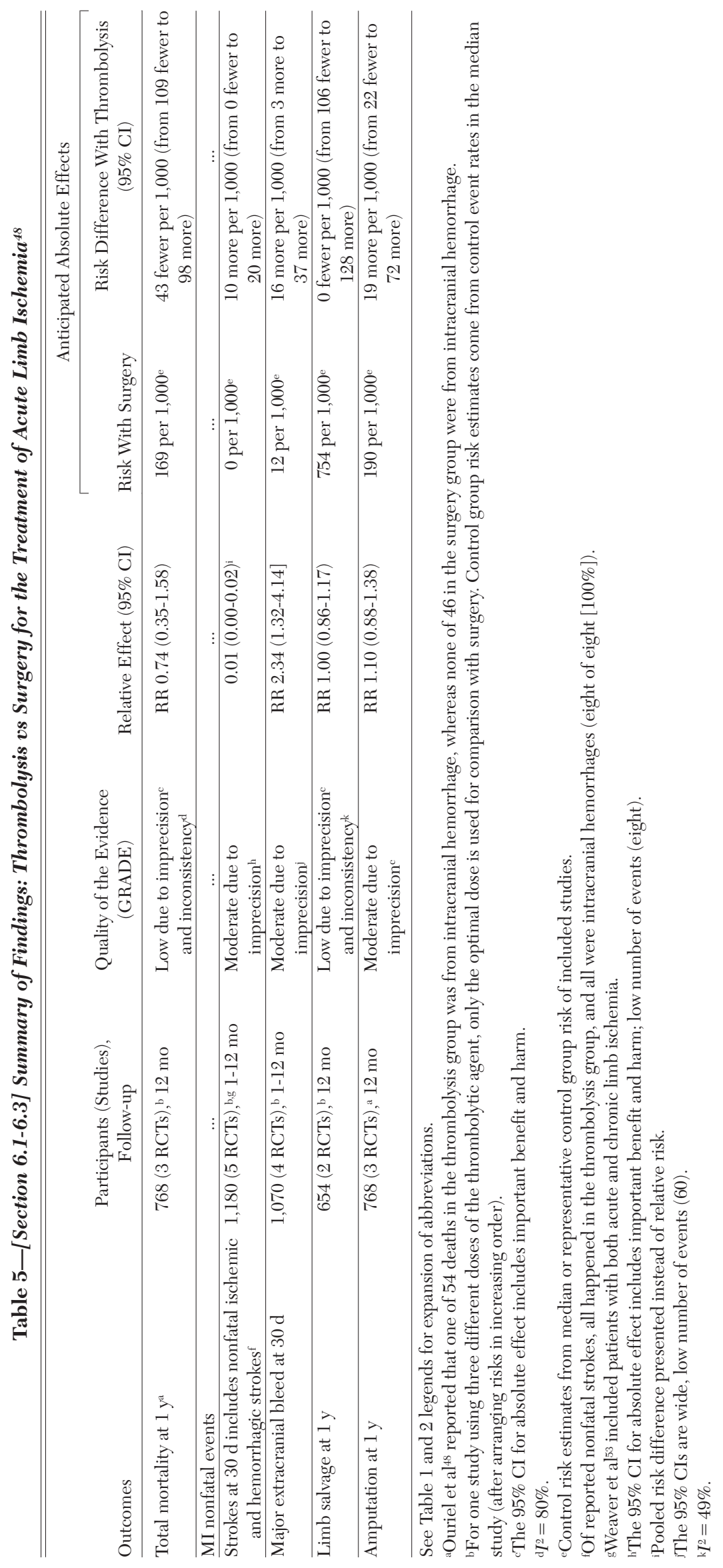




\subsection{Comparison of Intraarterial Thrombolytic Agents for Acute Limb Ischemia}

In the past, thrombolysis for acute limb ischemia was administered by IV; now this strategy has been replaced by catheter-directed thrombolysis. Evidence comparing the efficacy of different intraarterial thrombolytic agents for acute limb ischemia is limited. However, in a Cochrane systematic review, Robertson et al ${ }^{54}$ identified four randomized trials comparing recombinant tissue-type plasminogen activator (rt-PA), urokinase, or streptokinase for the management of acute lower-limb ischemia. ${ }^{55-58}$ Included was one small RCT comparing intraarterial streptokinase to intraarterial rt-PA in 40 patients with acute limb ischemia. ${ }^{55}$ With streptokinase, there was an increased rate of amputation at 30 days (seven of 20 vs one of 20; RR, 7.0; 95\% CI, 0.95-51.80). Results failed to demonstrate or exclude an effect of streptokinase vs intraarterial rt-PA on asymptomatic limb salvage, major hemorrhage, or death.

Initially, streptokinase was the most widely used agent, but since this study ${ }^{55}$ and because of other safety concerns (eg, allergic reactions), it has largely been replaced by urokinase and rt-PA. ${ }^{54}$ Three RCTs compared intraarterial urokinase to rt-PA for acute peripheral arterial occlusion. ${ }^{56-58}$ The overall quality for this comparison is low because of imprecision in outcome estimates as well as limitations in design and execution. Results failed to demonstrate or to exclude an effect of intraarterial rt-PA vs intraarterial urokinase on amputation, limb salvage, major hemorrhage, or death (Table S12).

\section{Recommendation}

6.1-6.3. In patients with acute limb ischemia due to arterial emboli or thrombosis, we suggest immediate systemic anticoagulation with unfractionated heparin over no anticoagulation (Grade 2C); we suggest reperfusion therapy (surgery or intraarterial thrombolysis) over no reperfusion therapy (Grade $2 \mathrm{C}$ ); and we recommend surgery over intraarterial thrombolysis (Grade 1B). In patients undergoing intraarterial thrombolysis, we suggest rt-PA or urokinase over streptokinase (Grade $2 \mathrm{C}$ ).

\subsection{ENdovascular REvascularization in Patients With Symptomatic PAD}

Patients with refractory claudication, rest pain, and ischemia often require revascularization for symptomatic relief and limb salvage. Increasingly, patients are undergoing PTA with or without stent placement. Few studies guide clinicians regarding type and duration of antithrombotic therapy following such proce- dures. Current practice is very heterogeneous and often is based on indirect evidence from studies in patients undergoing coronary stenting.

\subsection{Antithrombotic Therapy Following PTA With and Without Stent Procedures}

A Cochrane review ${ }^{59}$ pooled data from two early studies, including 356 patients undergoing lowerextremity PTA without stent placement, and found a possible reduction in reocclusion at 6 months in patients taking aspirin plus dipyridamole compared with placebo (OR, 0.69; 95\% CI, 0.44-1.10). ${ }^{60,61}$ Two other studies failed to demonstrate or exclude an effect of aspirin and dipyridamole vs phenprocoumon (vitamin $\mathrm{K}$ antagonist) in reocclusion at 6 months following PTA (OR, 0.78; 95\% CI, 0.43-1.41). ${ }^{62,63}$ One study failed to demonstrate or exclude an effect on 12-month reocclusion in patients taking ticlopidine compared with phenprocoumon (OR, 0.71; 95\% CI, 0.37-1.36). ${ }^{64}$ An additional study randomized 179 patients following PTA (pelvic or lower extremity) complicated by extensive dissection to IV unfractionated heparin vs subcutaneous nadroparin (a lowmolecular-weight heparin) administered for 1 week postprocedure (followed by 6 months of aspirin in each arm). ${ }^{65}$ Nadroparin was associated with a reduction in vessel restenosis/occlusion at 6 months $(\mathrm{OR}, 0.35$; 95\% CI, 0.19-0.65) but failed to demonstrate or exclude an effect on amputation (OR, 1.0; 95\% CI, 0.20-5.10).

We have identified no RCTs comparing antithrombotic agents post-PTA with stent placement. Indeed, it remains unclear whether PTA with stent placement is superior to PTA alone with respect to patient-important outcomes. In a recent metaanalysis of 10 RCTs, PTA plus routine stenting for superficial femoropopliteal arterial disease was associated with a possible reduction in restenosis (RR, 0.85; 95\% CI, 0.69-1.06) compared with PTA without routine stenting but failed to demonstrate or exclude an effect on need for target vessel revascularization (RR, 0.98; 95\% CI, 0.78-1.23).66

Nevertheless, stenting is performed frequently. Despite low-quality evidence regarding thienopyridines in patients undergoing PTA with stent placement for PAD, many interventionists provide a loading dose of clopidogrel in addition to aspirin preprocedure and then continue dual antiplatelet therapy for 1 to 3 months post-PTA (particularly if a stent is placed in a small peripheral vessel). The rationale for this practice is based on the results from coronary artery stenting trials (see section 3 of Vandvik et al ${ }^{4}$ in this supplement).

We are skeptical about extrapolating these data to all patients with PAD given differences in the 
risk of stent thrombosis (lower in stenting of largercaliber peripheral arteries compared with smaller coronary arteries), difference in stent types, and differing outcomes related to stent thrombosis (limb ischemia vs MI). Furthermore, dual antiplatelet therapy is associated with an increased risk of major bleeding compared with single antiplatelet therapy (see sections 2 and 3 of Vandvik et $\mathrm{al}^{4}$ in this supplement).

\section{Recommendation}

\subsection{For patients undergoing peripheral artery PTA with or without stenting, we recommend long-term aspirin (75-100 mg/d) or clopidogrel $(75 \mathbf{~ m g} / \mathrm{d})$ (Grade 1A). For patients undergoing peripheral artery PTA with stenting, we suggest single rather than dual antiplatelet therapy (Grade 2C).}

Values and preferences: Patients who place a high value on an uncertain reduction in the risk of limb loss and a relatively low value on avoiding a potential increased risk of bleeding are likely to choose to use dual antiplatelet therapy.

\subsection{ANTITHRombotic Therapy Following Peripheral Artery Bypass Graft Surgery}

In this section, we review evidence from studies evaluating antithrombotic therapy following peripheral bypass surgery. For the most part, these data do not suggest that recommendations for antithrombotic therapy following peripheral artery bypass surgery should differ from that in other patients with symptomatic PAD. One exception is the use of dual antiplatelet therapy in patients following prosthetic graft bypass surgery.

\section{Selection of Baseline Risk Estimate}

For the comparison of warfarin vs aspirin or clopidogrel plus aspirin vs aspirin following PAD surgery, we used as our baseline risk estimate the event rates from patients receiving aspirin in the Dutch Bypass Oral Anticoagulants or Aspirin (BOA) study normalized to 1 year. ${ }^{67}$ For the comparison of aspirin plus dipyridamole vs placebo, we calculated baseline risk estimates in the placebo group by applying the relative risk for placebo vs aspirin plus dipyridamole to the aforementioned aspirin baseline risk estimate. ${ }^{68}$

\subsection{Aspirin and Dipyridamole vs Placebo}

We used the data from the Cochrane review of six RCTs with a total of 966 patients $^{69-74}$ by Brown et al ${ }^{68}$ that evaluated the impact of aspirin and dipyridamole vs placebo in patients postinfrainguinal (venous or prosthetic) bypass graft surgery (for refractory claudication and limb salvage). The relative effects of aspirin plus dipyridamole vs aspirin alone have not been evaluated.

The overall quality of the evidence is low because of indirectness (loss of graft patency being a surrogate for amputation) and bias (Table 6, Table S13). Aspirin plus dipyridamole may result in 22 fewer graft occlusions per 1,000 patients (32 fewer to 12 fewer) treated for 12 months. Only one study provided data on amputation rates wherein aspirin plus dipyridamole compared with placebo for 12 months was associated with a possible reduction in amputations (34 fewer amputations per 1,000 patients treated [51 fewer to one more]). Pooled data from three studies reporting other vascular outcomes suggested that treatment with aspirin plus dipyridamole was associated with a possible reduction in nonfatal MI but failed to demonstrate or exclude an effect on nonfatal stroke. Aspirin plus dipyridamole was associated with a possible increase in bleeding (eight more major bleeding events per 1,000 treated [one fewer to 30 more]).

\subsection{Aspirin With or Without Dipyridamole vs Other Agents}

The same Cochrane review presented evidence from studies comparing aspirin with or without dipyridamole to other agents. ${ }^{68}$ These other agents included low-molecular-weight heparin, indobufen, pentoxifylline, and prostaglandins. All these studies failed to demonstrate or exclude an effect of these agents compared with aspirin with or without dipyridamole in long-term graft patency or major extracranial bleeding. Individual studies were underpowered for assessment of treatment differences in MI, stroke, or mortality.

\subsection{Clopidogrel Plus Aspirin vs Aspirin Alone}

The Clopidogrel and Acetylsalicyclate Acid in Bypass Surgery for Peripheral Arterial Disease (CASPAR) study randomized 851 patients undergoing unilateral below-knee bypass graft surgery for PAD to clopidogrel $(75 \mathrm{mg} / \mathrm{d})$ plus aspirin (75-100 mg/d) vs placebo plus aspirin. ${ }^{75}$ In the overall cohort, aspirin and clopidogrel failed to demonstrate or exclude an effect on limb amputation, nonfatal extracranial bleeding, or total mortality compared with aspirin alone (Table S14).

Randomization of patients in this trial was stratified according to graft type (venous or prosthetic), and the investigators undertook prespecified analysis of these subgroups. In the subgroup of patients 


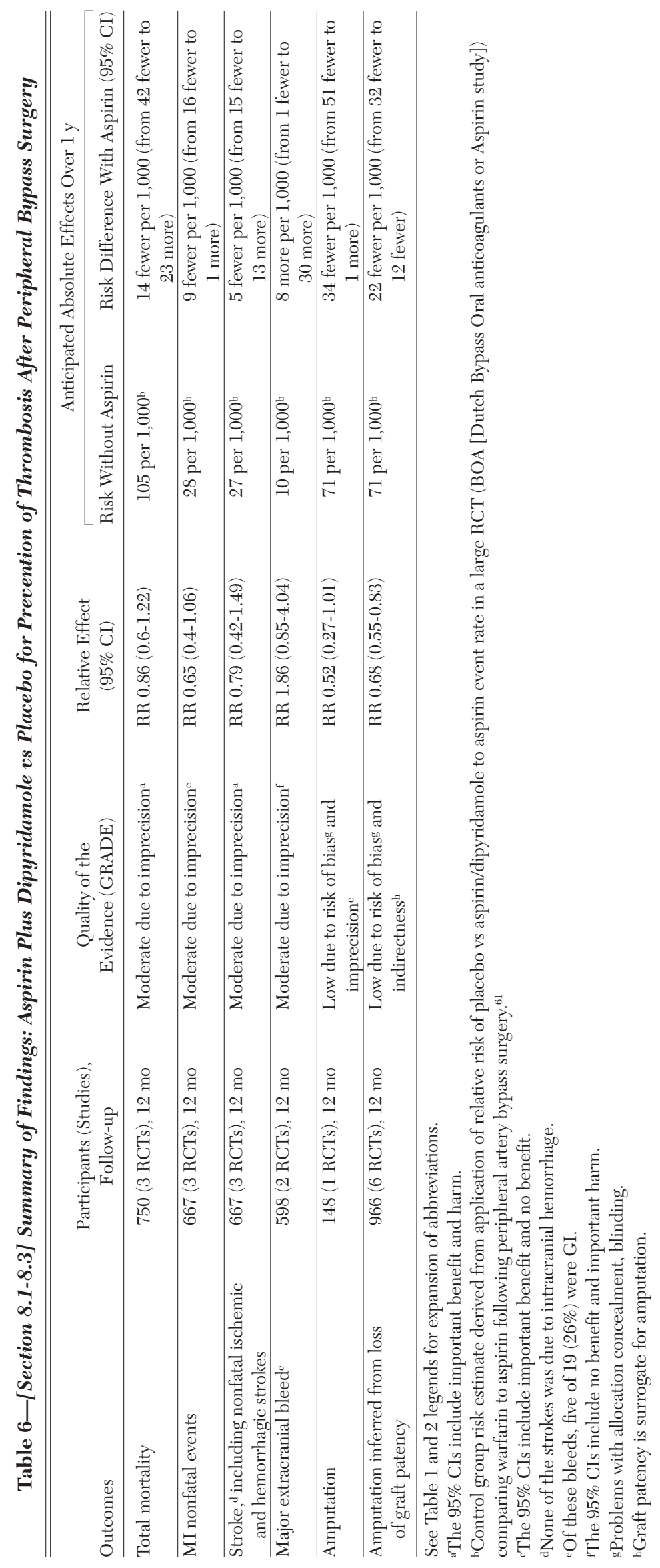


undergoing venous graft bypass $(\mathrm{n}=598)$, there were no significant differences in the rates of amputation, major bleeding, or death between the two treatment arms. However, in the subgroup of patients undergoing prosthetic graft bypass $(\mathrm{n}=253)$, there was a significant decrease in amputations in patients treated with clopidogrel plus aspirin (24 per 1,000 treated; 95\% CI, 35 fewer to three fewer; $P=.008$ using the Wald test for interaction) (Table S15). The substudy analysis failed to demonstrate or exclude an effect of clopidogrel and aspirin on total mortality or major extracranial bleeding. The quality of this evidence is considered low given very serious imprecision.

\subsection{Oral Anticoagulants vs Antiplatelet Agents}

The BOA study randomized 2,650 patients who had undergone infrainguinal bypass grafting to either high-intensity oral anticoagulation (with phenprocoumon or acenocoumarol [target international normalized ratio, 3-4.5]) or aspirin. ${ }^{67}$ Table S16 provides a review of the evidence and quality of this study. This study failed to demonstrate or exclude an effect of oral anticoagulation vs aspirin on all-cause mortality, nonfatal stroke, or limb loss. Although associated with a possible reduction in nonfatal MI, there was a significant increase in extracranial major bleeding events in the oral anticoagulation group.

Warfarin Plus Aspirin vs Warfarin Alone: Two studies compared warfarin plus aspirin to aspirin alone in patients after lower-limb surgical bypass. ${ }^{19,20}$ Both studies were included in the previous evaluation of the comparison of warfarin plus aspirin vs aspirin alone in patients with symptomatic PAD (see section 3).

In summary, the quality of the evidence for antiplatelet and antithrombotic therapy following PAD surgery for patient-important outcomes, such as amputation, limb loss, and mortality is low to moderate. Aspirin plus dipyridamole was associated with a possible reduction in amputation compared with placebo, but no comparison with aspirin alone has been performed. We did not identify any studies comparing aspirin alone to no aspirin. Aspirin plus clopidogrel was associated with a decrease in amputations over aspirin alone in a subgroup of patients undergoing prosthetic graft placement in one study. ${ }^{75}$ Warfarin with or without aspirin is associated with a significant increase in extracranial bleeding compared with aspirin alone. The impact of these therapies on other critical vascular outcomes (nonfatal MI or stroke) cannot be adequately assessed based on these studies. With the exception of a weak recommendation for clopidogrel plus aspirin for 1 year in patients undergoing below-knee prosthetic graft placement, our recommendations for long-term antithrombotic therapy following peripheral bypass surgery are the same as those for other patients with symptomatic PAD (see section 2).

Recommendation

8.1-8.4. We recommend one of the following antithrombotic regimens to be continued long term in most patients following peripheral artery bypass graft surgery over no antithrombotic treatment: aspirin 75 to $100 \mathrm{mg}$ daily or clopidogrel $75 \mathrm{mg}$ daily (all Grade $1 \mathrm{~A}$ ). We recommend single antiplatelet therapy over antiplatelet therapy and warfarin (Grade 1B). In patients undergoing below-knee bypass graft surgery with prosthetic grafts, we suggest clopidogrel $75 \mathrm{mg} / \mathrm{d}$ plus aspirin $(75-100 \mathrm{mg} / \mathrm{d})$ over aspirin alone for 1 year (Grade $2 \mathrm{C}$ ). For all other patients, we suggest single over dual antiplatelet therapy (Grade 2B).

\subsection{CARotid Artery Stenosis}

Carotid stenosis may coexist in asymptomatic patients as well as in symptomatic patients with CAD or PAD. Recent prevalence estimates range from $0.2 \%$ in men aged $<50$ years to $7.5 \%$ in men aged $\geq 80$ years. $^{76}$

\subsection{Primary Prevention of Cardiovascular Events}

As with patients with asymptomatic PAD, we consider the evidence for aspirin therapy for the primary prevention of vascular events and total mortality described in Vandvik et al ${ }^{4}$ applicable to patients with asymptomatic carotid stenosis (Table S2). Patients with asymptomatic carotid stenosis may be stratified into low, moderate, or high risk for vascular events as described in section 2 of the cited article. Our recommendations for primary prevention in patients with asymptomatic carotid stenosis, therefore, are identical to those for patients with asymptomatic PAD or at risk for CAD. Section 1.2 of Vandvik et $\mathrm{al}^{4}$ in this supplement provides a more-detailed discussion of the evidence.

\subsection{Antithrombotic Therapy for Secondary Prevention in Patients With Symptomatic Carotid Stenosis}

The article by Lansberg et $\mathrm{al}^{77}$ in this supplement provides a full description of the evidence and recommendations for antithrombotic therapy for secondary prevention in patients with symptomatic carotid stenosis. Recommendations are repeated here for readers' ease of use. 


\subsection{Antithrombotic Therapy for Secondary \\ Prevention in Patients Following \\ Carotid Endarterectomy}

We believe that the evidence for patients with symptomatic carotid stenosis also applies to patients following carotid endarterectomy (even if previously asymptomatic). Therefore, recommendations for therapy following carotid endartectomy are the same as for patients with symptomatic carotid stenosis.

There are no studies evaluating timing of initiation of antithrombotic therapy before or after endarterectomy. For recommendations regarding continuation and discontinuation of antithrombotic therapy and timing of reinitiation relative to surgery, see Douketis et $\mathrm{al}^{78}$ in this supplement.

For completeness, we summarize the limited direct evidence for antiplatelet therapy in patients following carotid endarterectomy. A Cochrane systematic review identified six RCTs comparing antiplatelet therapy to no antiplatelet therapy in patients with symptomatic or asymptomatic carotid stenosis undergoing carotid endarterectomy (with $\geq 3$ months of follow-up). ${ }^{79}$ Four of the trials tested aspirin (dose range, 50-1,300 mg), , 80 one trial tested aspirin (990 $\mathrm{mg}$ ) plus dipyridamole $(225 \mathrm{mg}),{ }^{84}$ and one trial tested indobufen $(400 \mathrm{mg}){ }^{85}$ Five of the six trials used placebo controls. Timing of initiation of antiplatelet therapy ranged from $12 \mathrm{~h}$ prior to carotid endarterectomy to up to 3 months after carotid endarterectomy; treatment and follow-up duration ranged from 6 to 54 months. Antiplatelet drugs were associated with a significant reduction in strokes (OR, 0.58; 95\% CI, 0.34-0.98); the estimated absolute effect was 34 fewer per 1,000 patients treated ( 2 fewer to 54 fewer). Results failed to demonstrate or exclude an effect of antiplatelet therapy on vascular mortality, nonfatal MI, or nonfatal extracranial hemorrhages. Overall quality of the evidence is low because of risk of bias, imprecision, and inconsistency.

Previously presented data in patients with vascular disease suggested no benefit and probable increased harm associated with increasing aspirin doses (section 2 of Vandvik et $\mathrm{al}^{4}$ ). In addition, the Aspirin and Carotid Endarterectomy trial randomly assigned 2,849 patients scheduled for endarterectomy to one of four doses of aspirin $(81,325,650$, and $1,300 \mathrm{mg}$ ). ${ }^{86}$ Aspirin was started before surgery and continued for 3 months. The combined rate of stroke, MI, and death was lower in the low-dose groups (81 and $325 \mathrm{mg}$ ) than in the high-dose groups at 30 days $(5.4 \%$ vs $7.0 \%, P=.07)$ and at 3 months (6.2\% vs $8.4 \%, P=.03)$. No RCTs measured patientimportant outcomes comparing clopidogrel vs aspirin or clopidogrel plus aspirin vs single antiplatelet therapy in patients undergoing carotid endarterectomy.
Recommendations

9.1. For persons with asymptomatic carotid stenosis, we suggest aspirin 75 to $100 \mathrm{mg}$ daily over no aspirin therapy (Grade $2 \mathrm{~B}$ ).

Remarks: Aspirin slightly reduces total mortality regardless of cardiovascular risk profile if taken over 10 years. In people at moderate to high risk of cardiovascular events, the reduction in MI is closely balanced with an increase in major bleeds. Whatever their risk status, people who are averse to taking medication over a prolonged time period for very small benefits will be disinclined to use aspirin for primary prophylaxis.

9.2-9.3. In patients with symptomatic carotid stenosis (including recent carotid endarterectomy), we recommend long-term antiplatelet therapy (clopidogrel [ $75 \mathrm{mg}$ once daily] or aspirinextended-release dipyridamole $[25 \mathrm{mg} / 200 \mathrm{mg}$ bid] or aspirin [75-100 mg once daily]) over no antiplatelet therapy (Grade 1A). We suggest either clopidogrel (75 mg once daily) or aspirinextended-release dipyridamole $(25 \mathrm{mg} / 200 \mathrm{mg}$ nid $)$ over aspirin (75-100 mg/day) (Grade $2 \mathrm{~B}$ ).

\section{ACKNOWLEDGMENTS}

Author contributions: As Topic Editor, Dr Alonso-Coello oversaw the development of this article, including the data analysis and subsequent development of the recommendations contained herein. Dr Alonso-Coello: contributed as Topic Editor.

Dr Bellmunt: contributed as a frontline clinician.

Dr McGorrian: contributed as a panelist.

Dr Anand: contributed as a panelist.

Dr Guzman: contributed as a panelist.

Dr Criqui: contributed as a panelist.

Dr Akl: contributed as a panelist.

Dr Vandvik: contributed as a panelist.

Dr Lansberg: contributed as a panelist.

Dr Guyatt: contributed as a panelist.

Dr Spencer: contributed as Deputy Editor.

Financial/nonfinancial disclosures: The authors of this guideline provided detailed conflict of interest information related to each individual recommendation made in this article. A grid of these disclosures is available online at http://chestjournal. chestpubs.org/content/141/2_suppl/e669S/suppl/DC1. In summary, the authors have reported to CHEST the following conflicts of interest: Dr Bullmunt received funds from Roche for a study unrelated to this guideline and received funds from Ferrer Laboratory for writing a public document related to cilostazol. Dr McGorrian has received conference travel support from Pfizer Ireland Ltd. Dr Guyatt is co-chair of the GRADE Working Group. Drs Alonso-Coello, Akl, and Vandvik are members of and prominent contributors to the GRADE Working Group. Drs Anand, Guzman, Criqui, Lansberg, and Spencer have reported that no potential conflicts of interest exist with any companies/organizations whose products or services may be discussed in this article.

Role of sponsors: The sponsors played no role in the development of these guidelines. Sponsoring organizations cannot recommend panelists or topics, nor are they allowed prepublication access to the manuscripts and recommendations. Guideline panel members, including the chair, and members of the Health \& Science Policy Committee are blinded to the funding sources. Further details on the Conflict of Interest Policy are available online at http://chestnet.org.

Other contributions: We acknowledge Saurabh Kalra for his important contribution to this article, especially in the section on 
acute limb ischemia. We acknowledge Kristian Thorlund, PhD, for assistance on presentation of continuous outcomes. We thank John Eikelboom, MD, for his contribution of estimates of total mortality for patients on or off aspirin (primary prevention) and Sam Schulman, MD, for assistance with interpretation of bleeding definitions. We thank John Wong, MD, for assistance in identifying cost-effectiveness implications.

Endorsements: This guideline is endorsed by the American Association for Clinical Chemistry, the American College of Clinical Pharmacy, the American Society of Health-System Pharmacists, the American Society of Hematology, and the International Society of Thrombosis and Hematosis.

Additional information: The supplement Tables can be found in the Online Data Supplement at http://chestjournal.chestpubs. org/content/141/2_suppl/e669S/suppl/DC1.

\section{REFERENCES}

1. Rothwell PM, Wilson M, Elwin CE, et al. Long-term effect of aspirin on colorectal cancer incidence and mortality: 20-year follow-up of five randomised trials. Lancet. 2010; 376(9754):1741-1750.

2. MacLean S, Mulla S, Akl EA, et al. Patient values and preferences in decision making for antithrombotic therapy: a systematic review: antithrombotic therapy and prevention of thrombosis, 9th ed: American College of Chest Physicians evidence-based clinical practice guidelines. Chest. 2012; $141(2)$ (suppl):e1S-e23S.

3. Guyatt GH, Norris SL, Schulman S, et al. Methodology for the development of antithrombotic therapy and prevention of thrombosis guidelines: antithrombotic therapy and prevention of thrombosis, 9th ed: American College of Chest Physicians evidence-based clinical practice guidelines. Chest. 2012;141(2)(suppl):50S-67S.

4. Vandvik PO, Lincoff AM, Gore JM, et al. Primary and secondary prevention of cardiovascular disease: antithrombotic therapy and prevention of thrombosis, 9th ed: American College of Chest Physicians evidence-based clinical practice guidelines. Chest. 2011;141(2)(suppl):e637S-e668S.

5. Leng GC, Fowkes FG, Lee AJ, Dunbar J, Housley E, Ruckley CV. Use of ankle brachial pressure index to predict cardiovascular events and death: a cohort study. BMJ. 1996;313(7070):1440-1444.

6. Newman AB, Shemanski L, Manolio TA, et al; The Cardiovascular Health Study Group. Ankle-arm index as a predictor of cardiovascular disease and mortality in the Cardiovascular Health Study. Arterioscler Thromb Vasc Biol. 1999;19(3):538-545.

7. Resnick HE, Lindsay RS, McDermott MM, et al. Relationship of high and low ankle brachial index to all-cause and cardiovascular disease mortality: the Strong Heart Study. Circulation. 2004;109(6):733-739.

8. Ogren M, Hedblad B, Isacsson SO, Janzon L, Jungquist G, Lindell SE. Non-invasively detected carotid stenosis and ischaemic heart disease in men with leg arteriosclerosis. Lancet. 1993;342(8880):1138-1141.

9. van der Meer IM, Bots ML, Hofman A, del Sol AI, van der Kuip DA, Witteman JC. Predictive value of noninvasive measures of atherosclerosis for incident myocardial infarction: the Rotterdam Study. Circulation. 2004;109(9):1089-1094.

10. Fowkes FG, Murray GD, Butcher I, et al; Ankle Brachial Index Collaboration. Ankle brachial index combined with Framingham Risk Score to predict cardiovascular events and mortality: a meta-analysis. JAMA. 2008;300(2):197-208.

11. Baigent C, Blackwell L, Collins R, et al; Antithrombotic Trialists' (ATT) Collaboration. Aspirin in the primary and secondary prevention of vascular disease: collaborative metaanalysis of individual participant data from randomised trials. Lancet. 2009;373(9678):1849-1860.
12. Rothwell PM, Fowkes FG, Belch JF, Ogawa H, Warlow CP Meade TW. Effect of daily aspirin on long-term risk of death due to cancer: analysis of individual patient data from randomised trials. Lancet. 2011;377(9759):31-41.

13. Raju NC, Sobieraj-Teague M, Hirsh J, O'Donnell M, Eikelboom J. Effect of aspirin mortality in primary prevention of cardiovascular disease. Am J Med. 2011;124(7):621-6329.

14. Sun X, Briel M, Walter SD, Guyatt GH. Is a subgroup effect believable? Updating criteria to evaluate the credibility of subgroup analyses. BMJ. 2010;340:c117.

15. CAPRIE Steering Committee. A randomised, blinded, trial of clopidogrel versus aspirin in patients at risk of ischaemic events. Lancet. 1996;348:1329-1339.

16. Sudlow CL, Mason G, Maurice JB, Wedderburn CJ, Hankey GJ. Thienopyridine derivatives versus aspirin for preventing stroke and other serious vascular events in high vascular risk patients. Cochrane Database Syst Rev. 2009;(4): CD001246.

17. Keller TT, Squizzato A, Middeldorp S. Clopidogrel plus aspirin versus aspirin alone for preventing cardiovascular disease. Cochrane Database Syst Rev. 2007;(3):CD005158.

18. Bhatt DL, Fox KA, Hacke W, et al; CHARISMA Investigators. Clopidogrel and aspirin versus aspirin alone for the prevention of atherothrombotic events. $N$ Engl J Med. 2006:354(16):1706-1717.

19. Johnson WC, Williford WO; Department of Veterans Affairs Cooperative Study \#362. Benefits, morbidity, and mortality associated with long-term administration of oral anticoagulant therapy to patients with peripheral arterial bypass procedures: a prospective randomized study. J Vasc Surg. 2002;35(3): 413-421.

20. Sarac TP, Huber TS, Back MR, et al. Warfarin improves the outcome of infrainguinal vein bypass grafting at high risk for failure. J Vasc Surg. 1998;28(3):446-457.

21. Anand S, Yusuf S, Xie C, et al; Warfarin Antiplatelet Vascular Evaluation Trial Investigators. Oral anticoagulant and antiplatelet therapy and peripheral arterial disease. $\mathrm{N} \mathrm{Engl} \mathrm{J} \mathrm{Med.}$ 2007:357(3):217-227.

22. Girolami B, Bernardi E, Prins MH, et al. Treatment of intermittent claudication with physical training, smoking cessation, pentoxifylline, or nafronyl: a meta-analysis. Arch Intern Med. 1999;159(4):337-345.

23. Jonason T, Bergström R. Cessation of smoking in patients with intermittent claudication. Effects on the risk of peripheral vascular complications, myocardial infarction and mortality. Acta Med Scand. 1987;221(3):253-260.

24. Gardner AW, Poehlman ET. Exercise rehabilitation programs for the treatment of claudication pain. A meta-analysis. JAMA. 1995;274(12):975-980.

25. Furukawa TA. From effect size into number needed to treat. Lancet. 1999;353(9165):1680.

26. Thorlund K, Walter S, Johnston B, Furukawa TA, Guyatt G. Pooling health-related quality of life outcomes in metaanalysis - a tutorial and review of methods for enhancing interpretability. Research Synthesis Methods. 2011.

27. Tamhane U, Meier P, Chetcuti S, et al. Efficacy of cilostazol in reducing restenosis in patients undergoing contemporary stent based PCI: a meta-analysis of randomised controlled trials. EuroIntervention. 2009:5(3):384-393.

28. Robless P, Mikhailidis DP, Stansby GP. Cilostazol for peripheral arterial disease. Cochrane Database Syst Rev. 2008;(1): CD003748

29. Squires H, Simpson E, Meng Y, Harnan S, Stevens J, Wong R. Cilostazol, Naftidrofuryl Oxalate, Pentoxifylline, and Inositol Nicotinate for Intermittent Claudication in People With Peripheral Arterial Disease. London, England: National Institute for Health and Clinical Excellence; 2011:1-252. 
30. Hiatt WR, Money SR, Brass EP. Long-term safety of cilostazol in patients with peripheral artery disease: the CASTLE study (Cilostazol: A Study in Long-term Effects). J Vasc Surg. 2008;47(2):330-336.

31. Beebe HG, Dawson DL, Cutler BS, et al. A new pharmacological treatment for intermittent claudication: results of a randomized, multicenter trial. Arch Intern Med. 1999; 159(17):2041-2050.

32. Money SR, Herd JA, Isaacsohn JL, et al. Effect of cilostazol on walking distances in patients with intermittent claudication caused by peripheral vascular disease. J Vasc Surg. 1998;27(2):267-274, discussion 274-275.

33. Strandness DE Jr, Dalman RL, Panian S, et al. Effect of cilostazol in patients with intermittent claudication: a randomized, double-blind, placebo-controlled study. Vasc Endovascular Surg. 2002;36(2):83-91.

34. O’Donnell ME, Badger SA, Sharif MA, Young IS, Lee B, Soong CV. The vascular and biochemical effects of cilostazol in patients with peripheral arterial disease. J Vasc Surg. 2009; 49(5):1226-1234.

35. Dawson DL, Cutler BS, Hiatt WR, et al. A comparison of cilostazol and pentoxifylline for treating intermittent claudication. Am J Med. 2000;109(7):523-530.

36. Pratt CM. Analysis of the cilostazol safety database. Am J Cardiol. 2001;87(12A):28D-33D.

37. Cosmi B, Conti E, Coccheri S. Anticoagulants (heparin, low molecular weight heparin and oral anticoagulants) for intermittent claudication. Cochrane Database Syst Rev. 2001; (3):CD001999.

38. Antonicelli R, Sardina M, Scotti A, Bonizzoni E, Paciaroni E; Italian CAP Study Group. Randomized trial of the effects of low-dose calcium-heparin in patients with peripheral arterial disease and claudication. Am J Med. 1999;107(3): 234-239.

39. Tesi M, Bronchi GF, Carini A, Morfini M, Cinotti S, Filiberti E. Efficacy and safety of a new low molecular weight heparin in the medium term treatment of atherosclerotic arteriopathy of the lower limbs. J Drug Dev. 1989;2(2):73-82.

40. Calabrò A, Piarulli F, Milan D, Rossi A, Coscetti G, Crepaldi G. Clinical assessment of low molecular weight heparin effects in peripheral vascular disease. Angiology. 1993;44(3):188-195.

41. Mannarino E, Pasqualini L, Innocente S, et al. Efficacy of low-molecular-weight heparin in the management of intermittent claudication. Angiology. 1991;42(1):1-7.

42. Palmieri G, Ambrosi G, Agrati AM, Ferraro G, Marcozzi S. A new low molecular weight heparin in the treatment of peripheral arterial disease. Int Angiol. 1988;7(3 suppl):41-47.

43. Momsen AH, Jensen MB, Norager CB, Madsen MR, Vestersgaard-Andersen T, Lindholt JS. Drug therapy for improving walking distance in intermittent claudication: a systematic review and meta-analysis of robust randomised controlled studies. Eur J Vasc Endovasc Surg. 2009;38(4):463-474.

44. Ruffolo AJ, Romano M, Ciapponi A. Prostanoids for critical limb ischaemia. Cochrane Database Syst Rev. 2010; (1):CD006544

45. Walker TG. Acute limb ischemia. Tech Vasc Interv Radiol. 2009;12(2):117-129.

46. Norgren L, Hiatt WR, Dormandy JA, Nehler MR, Harris KA, Fowkes FG. Inter-Society Consensus for the Management of Peripheral Arterial Disease (TASC II). J Vasc Surg. 2007;45(suppl S):S5-S67.

47. O'Connell JB, Quiñones-Baldrich WJ. Proper evaluation and management of acute embolic versus thrombotic limb ischemia. Semin Vasc Surg. 2009;22(1):10-16.

48. Berridge DC, Kessel D, Robertson I. Surgery versus thrombolysis for acute limb ischaemia: initial management. Cochrane Database Syst Rev. 2002;(3):CD002784.
49. Ouriel K, Veith FJ, Sasahara AA; Thrombolysis or Peripheral Arterial Surgery (TOPAS) Investigators. A comparison of recombinant urokinase with vascular surgery as initial treatment for acute arterial occlusion of the legs. $N$ Engl J Med. 1998;338(16):1105-1111.

50. Nilsson L, Albrechtsson U, Jonung T, et al. Surgical treatment versus thrombolysis in acute arterial occlusion: a randomised controlled study. Eur J Vasc Surg. 1992;6(2):189-193.

51. Ouriel K, Shortell CK, DeWeese JA, et al. A comparison of thrombolytic therapy with operative revascularization in the initial treatment of acute peripheral arterial ischemia. J Vasc Surg. 1994;19(6):1021-1030.

52. Ouriel K, Veith FJ, Sasahara AA; TOPAS Investigators. Thrombolysis or peripheral arterial surgery: phase I results. J Vasc Surg. 1996;23(1):64-75.

53. Weaver FA, Comerota AJ, Youngblood M, Froehlich J, Hosking JD, Papanicolaou G. Surgical revascularization versus thrombolysis for nonembolic lower extremity native artery occlusions: results of a prospective randomized trial. The STILE Investigators. Surgery versus Thrombolysis for Ischemia of the Lower Extremity. J Vasc Surg. 1996;24(4):513-523.

54. Robertson I, Kessel DO, Berridge DC. Fibrinolytic agents for peripheral arterial occlusion. Cochrane Database Syst Rev. 2010;(3):CD001099.

55. Berridge DC, Gregson RH, Hopkinson BR, Makin GS Randomized trial of intra-arterial recombinant tissue plasminogen activator, intravenous recombinant tissue plasminogen activator and intra-arterial streptokinase in peripheral arterial thrombolysis. Br J Surg. 1991;78(8):988-995

56. Mahler F, Schneider E, Hess H; Steering Committee, Study on Local Thrombolysis. Recombinant tissue plasminogen activator versus urokinase for local thrombolysis of femoropopliteal occlusions: a prospective, randomized multicenter trial. J Endovasc Ther. 2001;8(6):638-647.

57. Meyerovitz MF, Goldhaber SZ, Reagan K, et al. Recombinant tissue-type plasminogen activator versus urokinase in peripheral arterial and graft occlusions: a randomized trial. Radiology. 1990;175(1):75-78.

58. Schweizer J, Altmann E, Stösslein F, Florek HJ, Kaulen R. Comparison of tissue plasminogen activator and urokinase in the local infiltration thrombolysis of peripheral arterial occlusions. Eur J Radiol. 1996;22(2):129-132.

59. Dörffler-Melly J, Koopman MM, Prins MH, Büller HR. Antiplatelet and anticoagulant drugs for prevention of restenosis/reocclusion following peripheral endovascular treatment. Cochrane Database Syst Rev. 2005;(1):CD002071.

60. Heiss HW, Just H, Middleton D, Deichsel G. Reocclusion prophylaxis with dipyridamole combined with acetylsalicylic acid following PTA. Angiology. 1990;41(4):263-269.

61. Study Group on Pharmacological Treatment After TPA. Platelet inhibition with ASA/dipyridamole after percutaneous balloon angioplasty in patients with symptomatic lower limb arterial disease. A prospective double-blind trial. Eur J Vaso Surg. 1994;8(1):83-88.

62. Do DD, Mahler F. Low-dose aspirin combined with dipyridamole versus anticoagulants after femoropopliteal percutaneous transluminal angioplasty. Radiology. 1994;193(2):567-571.

63. Pilger E, Lammer J, Bertuch $\mathrm{H}$, et al. Nd:YAG laser with sapphire tip combined with balloon angioplasty in peripheral arterial occlusions. Long-term results. Circulation. 1991; 83(1):141-147.

64. Schneider E. Rezidivprophylaxe nach perkutaner transluminaler Angioplastie (PTA): antikoagulation versus ticlopidin. In: Huber H, ed. Fortschritte in der Angiologie. Bern, Switzerland: Sage; 1987:355-356.

65. Schweizer J, Müller A, Forkmann L, Hellner G, Kirch W. Potential use of a low-molecular-weight heparin to prevent 
restenosis in patients with extensive wall damage following peripheral angioplasty. Angiology. 2001;52(10):659-669.

66. Kasapis C, Henke PK, Chetcuti SJ, et al. Routine stent implantation vs. percutaneous transluminal angioplasty in femoropopliteal artery disease: a meta-analysis of randomized controlled trials. Eur Heart J. 2009;30(1):44-55.

67. Dutch Bypass Oral Anticoagulants or Aspirin (BOA) Study Group. Efficacy of oral anticoagulants compared with aspirin after infrainguinal bypass surgery (The Dutch Bypass Oral Anticoagulants or Aspirin Study): a randomised trial. Lancet. 2000;355(9201):346-351.

68. Brown J, Lethaby A, Maxwell H, Wawrzyniak AJ, Prins MH. Antiplatelet agents for preventing thrombosis after peripheral arterial bypass surgery. Cochrane Database Syst Rev. 2008; (4):CD000535.

69. Clyne CA, Archer TJ, Atuhaire LK, Chant AD, Webster JH. Random control trial of a short course of aspirin and dipyridamole (Persantin) for femorodistal grafts. Br J Surg. 1987; 74(4):246-248.

70. Goldman M, McCollum C. A prospective randomized study to examine the effect of aspirin plus dipyridamole on the patency of prosthetic femoro-popliteal grafts. Vasc Surg. $1984 ; 18(4): 217-221$.

71. Donaldson DR, Salter MCP, Kester RC, et al. The influence of platelet inhibition on the patency of femoro-popliteal Dacron bypass grafts. Vasc Surg. 1985;19(4):224-230.

72. Green RM, Roedersheimer LR, DeWeese JA. Effects of aspirin and dipyridamole on expanded polytetrafluoroethylene graft patency. Surgery. 1982;92(6):1016-1026.

73. Kohler TR, Kaufman JL, Kacoyanis G, et al. Effect of aspirin and dipyridamole on the patency of lower extremity bypass grafts. Surgery. 1984;96(3):462-466.

74. McCollum C, Alexander C, Kenchington G, Franks PJ, Greenhalgh R. Antiplatelet drugs in femoropopliteal vein bypasses: a multicenter trial. J Vasc Surg. 1991;13(1):150-162.

75. Belch JJ, Dormandy J, Biasi GM, et al. Results of the randomized, placebo-controlled clopidogrel and acetylsalicylic acid in bypass surgery for peripheral arterial disease (CASPAR) trial. J Vasc Surg. 2010;52(4):825-833.

76. de Weerd M, Greving JP, Hedblad B, et al. Prevalence of asymptomatic carotid artery stenosis in the general popula- tion: an individual participant data meta-analysis. Stroke. 2010;41(6):1294-1297.

77. Lansberg MG, O'Donnell MJ, Khatri P, et al. Antithrombotic and thrombolytic therapy for ischemic stroke: antithrombotic therapy and prevention of thrombosis, 9th ed: American College of Chest Physicians evidence-based clinical practice guidelines. Chest. 2012;141(2)(suppl):e601S-e636S.

78. Douketis JD, Spyropoulos AC, Spencer FA, et al. Perioperative management of antithrombotic therapy: antithrombotic therapy and prevention of thrombosis, 9th ed: American College of Chest Physicians evidence-based clinical practice guidelines. Chest. 2012;141(2)(suppl):e326S-e350S.

79. Engelter S, Lyrer P. Antiplatelet therapy for preventing stroke and other vascular events after carotid endarterectomy. Cochrane Database Syst Rev. 2003;(3):CD001458.

80. Fields WS, Lemak NA, Frankowski RF, Hardy RJ. Controlled trial of aspirin in cerebral ischemia. Part II: surgical group. Stroke. 1978;9(4):309-319.

81. Boysen G, Sørensen PS, Juhler M, et al. Danish very-lowdose aspirin after carotid endarterectomy trial. Stroke. 1988; 19(10):1211-1215.

82. Kretschmer G, Pratschner T, Prager M, et al. Antiplatelet treatment prolongs survival after carotid bifurcation endarterectomy. Analysis of the clinical series followed by a controlled trial. Ann Surg. 1990;211(3):317-322.

83. Lindblad B, Persson NH, Takolander R, Bergqvist D. Does low-dose acetylsalicylic acid prevent stroke after carotid surgery? A double-blind, placebo-controlled randomized trial. Stroke. 1993;24(8):1125-1128.

84. Harker LA, Bernstein EF, Dilley RB, et al. Failure of aspirin plus dipyridamole to prevent restenosis after carotid endarterectomy. Ann Intern Med. 1992;116(9):731-736.

85. Pratesi C, Pulli R, Milanesi G, Lavezzari M, Pamparana F, Bertini D. Indobufen versus placebo in the prevention of restenosis after carotid endarterectomy: a double-blind pilot study. J Int Med Res. 1991;19(3):202-209.

86. Taylor DW, Barnett HJ, Haynes RB, et al. Low-dose and high-dose acetylsalicylic acid for patients undergoing carotid endarterectomy: a randomised controlled trial. ASA and Carotid Endarterectomy (ACE) Trial Collaborators. Lancet. 1999;353(9171):2179-2184. 